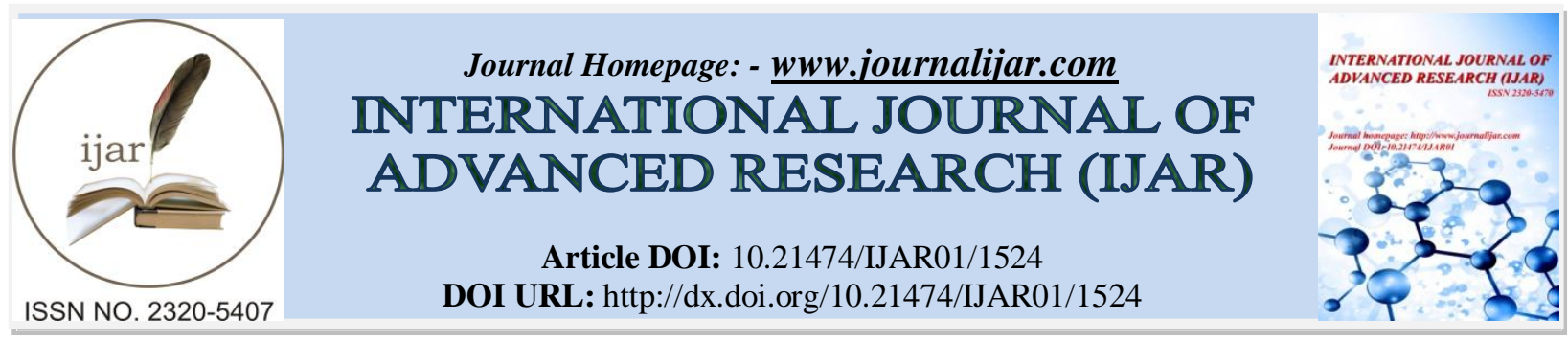

RESEARCH ARTICLE

\title{
ARE STUDENTS BECOMING SLAVES OF TECHNOLOGY?
}

*Pooja N, Kajal U, Supriya Y, Reshma T and Shailaja G.

Department of Microbiology, K. J. Somaiya College of Science and Commerce, Vidyavihar, Mumbai- 400077, Maharashtra, India.

\section{Manuscript Info}

Manuscript History

Received: 12 July 2016

Final Accepted: 19 August 2016

Published: September 2016

Key words:-

Nomophobia, College students, Mobile phone dependence.

\section{Abstract}

Mobile phones have become a necessary commodity. Right from the simple phone to smart phones each have some feature that attracts the crowd. People have become so used to mobile phones that it is difficult for them to imagine staying without it. Anxiousness, anxiety, stress, depression are some of the consequences of not using mobile phones. Nomophobia has become an emerging psychological disorder. The objective of the study is to determine the dependence of mobile phone on college students in Mumbai, India. Data was collected in two parts. One in the form of a questionnaire and second collecting experience from participants refrained from using mobile phones for 24 hours. The study population of 500 students was considered out of which $47 \%$ were males and $53 \%$ females. $62 \%$ participants use mobile phones for more than 4 hours; $69 \%$ feel lonely when not using mobile phones and $57 \%$ are at a risk of developing Nomophobia. Study is indicative of dependence of Nomophobia on youth. Further studies need to be performed to explore psychological aspects of Nomophobia. Research was further carried ahead with a small group of students and it was found that the students miss their mobile phones and use alternate gadgets to access the internet or social media.

Copy Right, IJAR, 2016, All rights reserved.

\section{Introduction:-}

Man created new Technology and Devices according to their need. Inventions were made according to the need of man since the Stone Age period. Fire, wheel, electricity etc are few inventions which were made for survival. But most of the inventions were for the luxury of humans. Mobile phone is one such invention which was done with the purpose of obtaining a helping hand but has now become an obligation. Mobile phones were introduced in the market in 1980s, but their use spread only in the mid-1990s (Pavithra et al, 2015). The earlier mobile phones now have now evolved to smart phones and more modernized are tabs and I-pads. Today's youth use mobile phones not just to call people but for varied other uses. Internet has brought the world closer. Social media has become an important commodity after food, clothing and shelter. Every minute detail about one's life has to be uploaded on the social media. Listening to music, accessing mails, clicking pictures, reading EBooks, documents, searching information on the internet, playing games are other secondary uses of the mobile phones. The $2 \mathrm{G}$ user base in India has now shifted to $3 \mathrm{G}$ and $4 \mathrm{G}$. Speed is the most important factor. The $3 \mathrm{G}$ and $4 \mathrm{G}$ users in India are rapidly gaining market (Harshith Mallya, 2015).

Corresponding Author:- Pooja N.

Address:- Department of Microbiology, K. J. Somaiya College of Science and Commerce, Vidyavihar, Mumbai- 400077, Maharashtra, India. 
The fact that mobile phones are a boon to mankind cannot be ruled out. But overuse of mobiles can lead to Nomophobia. Nomophobia i.e. No-Mobile Phone Phobia is the irrational fear of being out of mobile phone contact. The addiction of mobile phone is the cause of this phobia. The termed was coined in 2010 by an UK post Office which was commissioned by an organisation YouGov, to study the anxieties suffered by mobile phone users, (Tim Elmore, 2014). They found that in Britain 53\% of users become anxious if they lose their mobile phones, run out of battery or have no network coverage and no credit, (Katherine B., 2008). People who tend to experience this phobia are prone to feel insecure or have lack of self-control, discipline and are very impatient. Some of the severe health implications are headache, dizziness, earache, ache in the wrist due to constant typing, blurring of vision by the radiation of mobile phones. Some people often feel uncomfortable, anxious, and nervous if they don't use their phones, (Kuss DJ.,et.al.,2011). Checking the phone has become a priority for most of the people as soon as they wake up. Many people are attached to their phone for most hours of the day. The constant use of this new technology in the form of mobile phones and tabs has lead to change in behavior of individuals and also their social outlooks.

The following study was based on the above stated lines and was focused to find out the dependence of mobile phones among students in the age group 16 to 23 years. The case study was carried out in Somaiya College Campus, Vidyavihar, Mumbai, India. Right from keeping a tab on recent activities in college to the recent activities in the society, mobiles are an important tool for most of the people.

\section{Materials and Methods:-}

The following study was carried out in two parts to study the dependence of mobile phone among students of Somaiya College, Vidyavihar, Mumbai, India.

Part A:- Students from various streams were randomly chosen for the study. They ranged from 16 to 23 years of age. A questionnaire was designed for the study which was first subjected to a small group of students and then after the modification the questionnaire was given to the students of the college. A sample set of 500 students was considered. The questionnaire had 10 questions which were targeted for obtaining general information about the implication of students' psychology about Mobile phones. The demographic and psychographic aspect of the students was studied. The demographic variable was the Age and Gender and the Psychographic variable was focused on the use of mobile phones, its dependence and the anxiety caused by its use. The questionnaire had questions which were based upon the duration of use of mobile phone, the various reasons associated with its use; whether it is the first priority of the individual to check their phone as soon as they get up, what happens when the internet connectivity is not available or when they lose the mobile phone, etc.

Part B:- Along with this a small group of individuals were asked to deposit their phone as a part of the study for 24 hours and their responses were recorded.

\section{Result:-}

The study was conducted at Somaiya College campus amongst students of the college. The age group included in the study was between 16-23 years. Mean age of participants $21.6+/-3.1$. The study was performed on 500 students comprising of $47 \%$ males and $53 \%$ females. The study included $44.5 \%$ postgraduate and $55.5 \%$ under graduate students. Majority of the participants started using smart phones at the age of 16 years.

According to the data obtained, the average number of hours spends on the mobile phone was from 2 to 5 hours. Nomophobic scores were higher in students who used mobile phones for more than 3 hours compared to students using for less than 3 hours in a day. The percentages of various uses of mobile phones for participants are as follows: for internet (45\%), social networking (25\%), camera (15\%) and other multiple reasons $(15 \%) .51 .4 \%$ of the participants were ready to participate in NO MOBILE DAY challenge; whereas $48.6 \%$ were not ready. There were $50 \%$ of the participants checking phone very often. About $41.3 \%$ of the participants get panic attack when they lose their phone and about $19.5 \%$ of the participants buy new phone within 24 hours.

There were $47.5 \%$ of the participants who feel lonely without phone. People tend lose their concentration, connectedness and are at stress when they lose their phone. There were $55.4 \%$ participants using phone while charging, $13.7 \%$ while driving, $8.95 \%$ in restricted areas and $16.55 \%$ during walking. 
Table 1:- Distribution of subjects based on pattern of mobile usage.

$\mathbf{N}=500$

\begin{tabular}{|l|l|l|}
\hline Sr. No. & Pattern of mobile usage & Number of students \\
\hline 1. & Spending more than 4 hours & 309 \\
\hline 2. & Mobile phones with internet, social networking, camera & 408 \\
\hline 3. & Frequent checking of phone & 362 \\
\hline 4. & Feeling aloof when not using phone & 344 \\
\hline 5. & Participation in NO MOBILE DAY & 230 \\
\hline
\end{tabular}

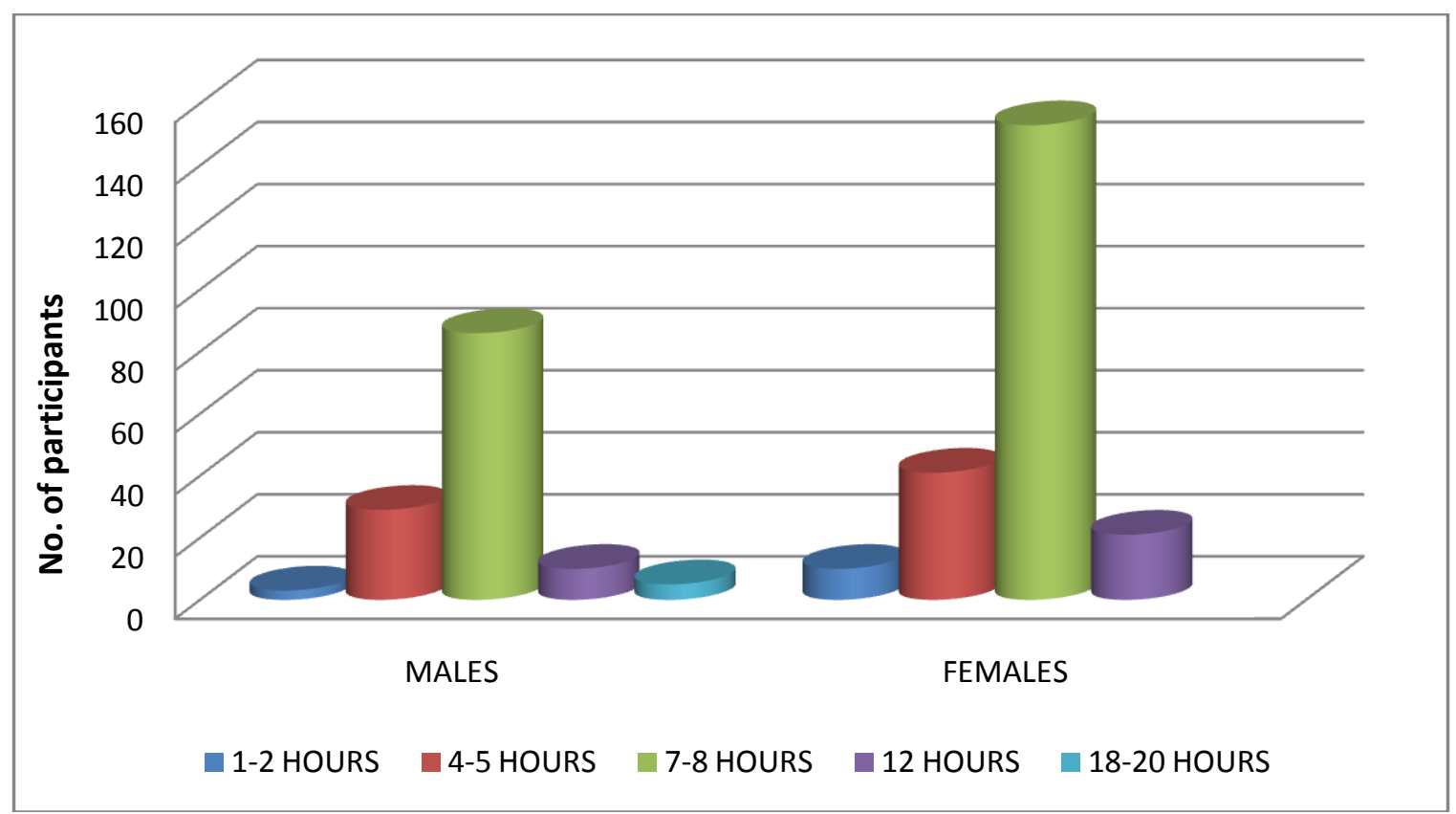

Figure 1:- Number of hours spend on the phone.

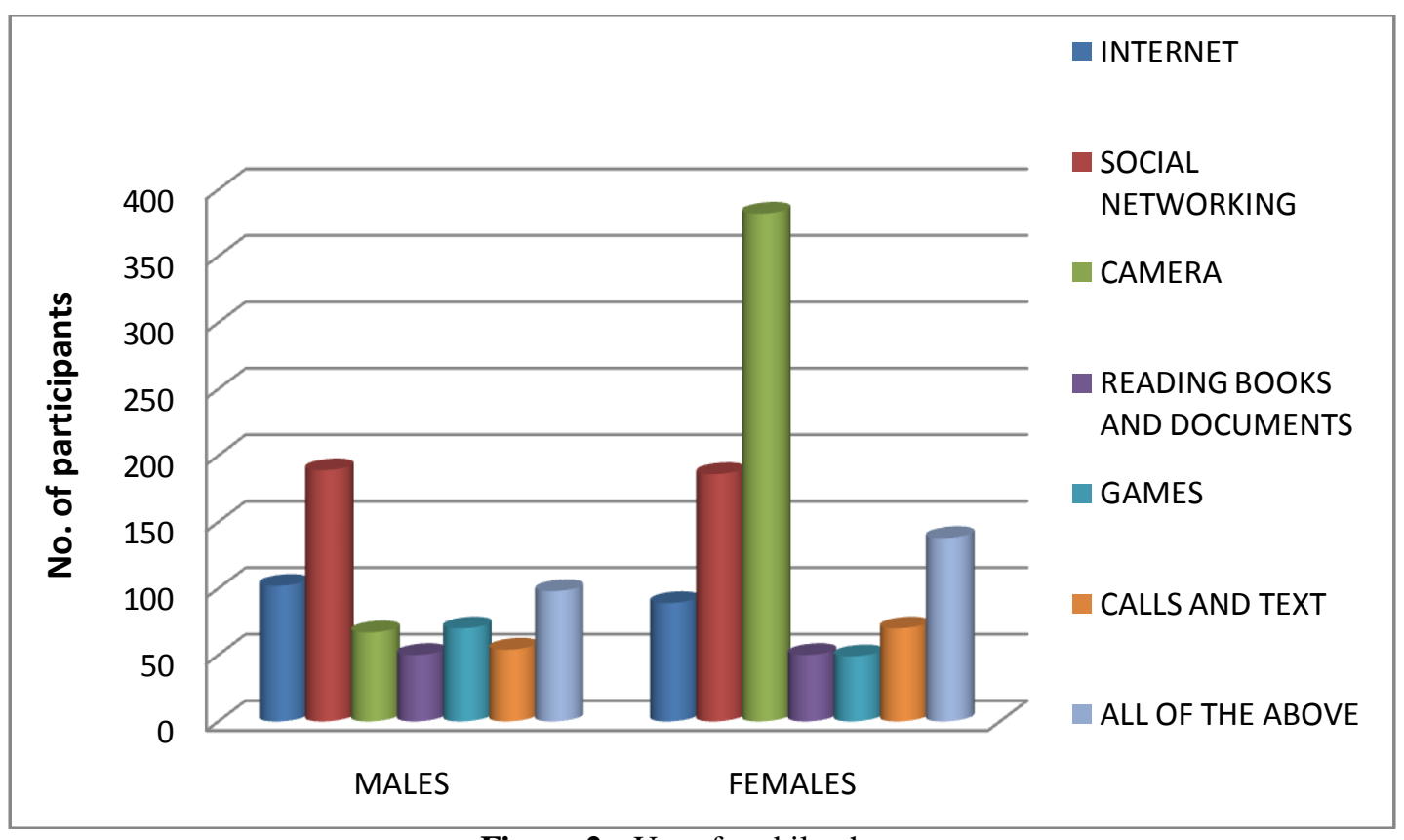

Figure 2:- Use of mobile phone. 


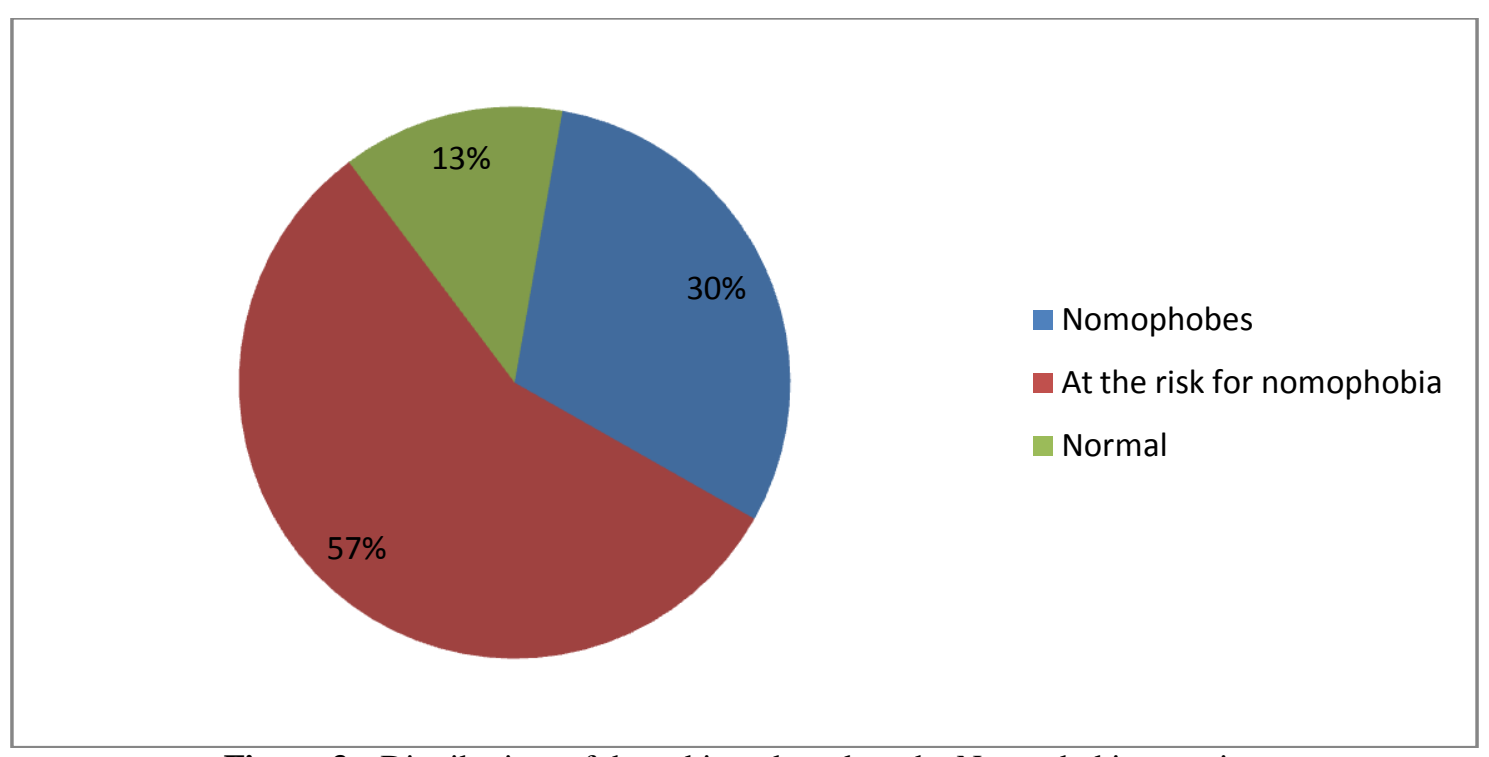

Figure 3:- Distribution of the subjects based on the Nomophobia severity.

\section{Discussion:-}

Nomophobia- that is fear of losing connectedness with the world is one of the recently emerging psychological disorders. Nomophobia is situational phobia. (King.et.al.,2010). According to the study, 57\% of people are found to be at the risk of developing Nomophobia; 39\% people are Nomophobic and 13\% people are normal. Unlike in a study conducted by Bivin J.B.et.al. (2013), on male under graduate students of Health Sciences showed $64 \%$ to be at risk of Developing Nomophobia. (Bivin J.B.et.al.,2013). Also in a study conducted on medical students revealed that out of 200 students, 39.5\% were Nomophobic. (Pavithra MB.et.al.,2015). The result of the study shows that females are more addicted to cell phones than males irrespective of the age. A study from United Kingdom on 2163 people showed that $53 \%$ of the subjects tend to be anxious when they lose their mobile phones or have no credit or when the battery is drained and in areas where no network is available. Also, according to the study, 58\% men and $48 \%$ women suffer from the phobia and an additional 9\% feel stressed when their phone is switched off. About 55\% of those surveyed cited keeping in touch with their family or friends was the main reason for their anxiousness when they couldn't use their phone (Katherine B., 2008). Most of the participants used their phone for two main purpose i.e. Camera and internet. Use of social media was also one of the significant reasons. Females lead the table keeping males in the backseat. Also this result is contradictory to the research conducted by Beranuy M.et.al., in 2009, which states problematic phone use was found lower in female student as compared to male student, (Beranuy M. et.al.,2009).

Participants in the study started using smart phones at the age of 16. In Uzgoren's study, the age for the first mobile phone use was 13-16. (Uzgoren E.et.al.,2012). According to a study done in Pakistan, the mobile phone addiction level was higher in the students whose age for first mobile phone was 13 and less than those who received their first phone at an age of 16.(Sahin S. et.al.2013). According to the study, most of the males would buy a cell phone within 24 hours of losing their cell phone as compared to females. On the other hand, maximum females get panic attack after losing their cell phone. As compared to males, females feel lonely without using their cell phone. Also for few people, they falling down is more dangerous than their phones falling down but also the phone falling down is a very dangerous thing for quite a few people. If the phone internet is not working, most of the students spend time with family only after calling the operator about fixing the Wi-Fi connection.

According to the second part of the study where the phone was kept away from the participants for 24 hours, initially most of the participants were absolutely fine with it. But as time passed by most of them felt something missing. Travelling by train is a part of the daily schedule of the participants and listening to music is the part of the travel. The participants revealed them missing their phone during their travel. A few of the participants used alternative for accessing internet i.e. laptop or mobile phone of family members. 
Owing to the various advantages that smart-phones offer, it is very lucrative for the youth. Keeping their addiction in control is upto their discretion. Individuals can keep a tab on their activities so that they don't become Nomophobic. With the results obtained from the study, the risk of people becoming Nomophobic is higher and hence measures need to be taken.

\section{Conclusion:-}

Inventions have their own pros and cons. Globalization and internet has brought the world closer and mobile phones have brought it handy. Almost all the information can be obtained only by a few clicks on the phone. Most of the jobs can be done quickly and efficiently with the use of mobile. But on the other hand, constant use can prove to be addictive and can lead to Nomophobia. The study indicates the dependence of the youth on mobile phones and Nomophobia can prove to be a risk in near future. Although the study is just qualitative and multicentric studies are required to establish a person to be Nomophobic, the possibility cannot be ruled out.

\section{References:-}

1. Sanjay Dixit, Harish Shukla, AK Bhagwat, Arpita Bindal, Abhilasha Goyal, Alia K Zaidi, Akansha Shrivastava. A Study to Evaluate Mobile Phone Dependence Among Students of a Medical College and Associated Hospital of Central India. Indian Journal of Community Medicine. (35), 2009. 339-341.

2. Bivin.J.B, Preeti Mathew, Praveen C. Thulasi, Jinto P. NOMOPHOBIA - Do We Really Need To Worry About?. Reviews of Progress. (1), 2013. 01-05.

3. Pavithra MB, Suwarna M, Mahadeva Murthy TS. A Study on Nomophobia - Mobile Phone Dependence, Among Students of a Medical College in Bangalore. Ntl J of Community Med 2015; 6(3):340- 344.

4. Caglar Yildirim. Exploring the dimensions of nomophobia: Developing and validating a questionnaire using mixed methods research. Graduate Thesis and Dissertations. 2014.01-62.

5. Choy, Y., Fyer, A. J., \& Lipsitz, J. D. Treatment of specific phobia in adults. Clinical psychology review, 27(3), 2007. 266-286.

6. King, A. L. S., Valença, A. M., \& Nardi, A. E. Nomophobia: the mobile phone in panic disorder with agoraphobia: reducing phobias or worsening of dependence?. Cognitive and Behavioral Neurology, 23(1), 2010. 52-54.

7. King, A. L. S., Valença, A. M., Silva, A. C. O., Baczynski, T., Carvalho, M. R., \& Nardi, A.E. Nomophobia: Dependency on virtual environments or socialphobia?. Computers in Human Behavior, 29(1), 2013. $140-144$.

8. King, A. L. S., Valença, A. M., Silva, A. C., Sancassiani, F., Machado, S., \& Nardi, A. E. "Nomophobia": Impact of Cell Phone Use Interfering with Symptoms and Emotions of Individuals with Panic Disorder Compared with a Control Group. Clinical practice and epidemiology in mental health: CP \& EMH, $10,2014$. 28-35.

9. Dixit, Sanjay; Shukla, Harish; Bhagwat, AK; Bindal, Arpita; Goyal, Abhilasha; Zaidi, Aliak; Shrivastava, Akansha. "A Study to Evaluate Mobile Phone Dependence among Students of a Medical College and Associated Hospital of Central India". Indian Journal of Community Medicine. April, 35 (2): 2010. $339-41$.

10. Walsh, S. P., White, K. M., \& McD Young, R. Needing to connect: The effect of self and others on young people's involvement with their mobile phones. Australian journal of psychology, 62(4), 2010. 194-203.

11. Macro - market analysis and consumer research organization. A report on study of mobile phone usage among the teenagers and youth in Mumbai, April-May-2004.

12. Beranuy M, Oberst U, Carbonell X, Chamarro A. Problem- atic Internet and mobile phone use and clinical symptoms in college students: the role of emotional intelligence. Comput Hum Behav. 2009; 25(5): $1182-1187$.

13. Sahin S, Ozdemir K, Unsal A, Temiz N. Evaluation of mo- bile phone addiction level and sleep quality in university students. Pak J Med Sci 2013;29(4):913-918.

14. Uzgoren E. Sengur M. Yigit U. The factors affecting the demand of mobile phones by university students - An implementation on the students of Dumlupinar University, AfyonKocatepe University. Economics and Administration Faculty J. 2012;14:55-72.

15. Katharine B. Phone-reliant Britons in the grip of nomophobia, The independent. March 31, 2008. 